\title{
Goma Xanthana
}

\author{
Flávia Silva Cunha
}

Instituto de Química, Universidade Federal da Bahia, Campus de Ondina, Salvador - BA - Brasil, CEP 40170-290 (???@ufba.br)

\section{Objetivo}

Dimensionar pesquisas já desenvolvidas relacionadas com a Goma Xantana e relacionar pesquisas com preparação de componentes contendo radicais sacarídeos.

\section{Aspectos tecnológicos}

A goma xanthana é o produto obtido pela fermentação de carboidratos pelas bactérias Xanthomonas campestris.

$\mathrm{Na}$ indústria de alimentos é utilizada como espessante, estabilizante e emulsificante.

\section{Escopo}

Por se tratar de um tema relacionado à bioquímica, foi feita também uma análise com as Classificações Internacionais para conseguir uma pesquisa mais completa.

Foram utilizadas as palavras-chave gum* xanthan* e o código de classificação internacional C08B37 no banco de dados Espacenet, sendo encontradas 249 patentes em dezembro de 2007. No entanto, somente 144 foram possíveis de serem lidas no site do Espacenet.

Tabela de pesquisa por palavras-chave e código de classificação internacional

\begin{tabular}{ll}
\hline Palavras-chave e código & EP \\
\hline gum* xanthan* polysaccharid* product* & 138 \\
gum* xanthan* ferment* & 185 \\
gum* xanthan* product* & 782 \\
gum* xanthan* polysaccharid* & 515 \\
gum* xanthan* & 3434 \\
gum* xanthan* polysaccharid* ferment* & 42 \\
gum* xanthan* and C12P19/00 & 249 \\
gum* xanthan* and C12N1/20 & 33 \\
gum* xanthan* and C08B37/00 & 294 \\
\hline
\end{tabular}




\section{Resultados e Discussão}

1. Evolução Anual de Depósitos de Patentes

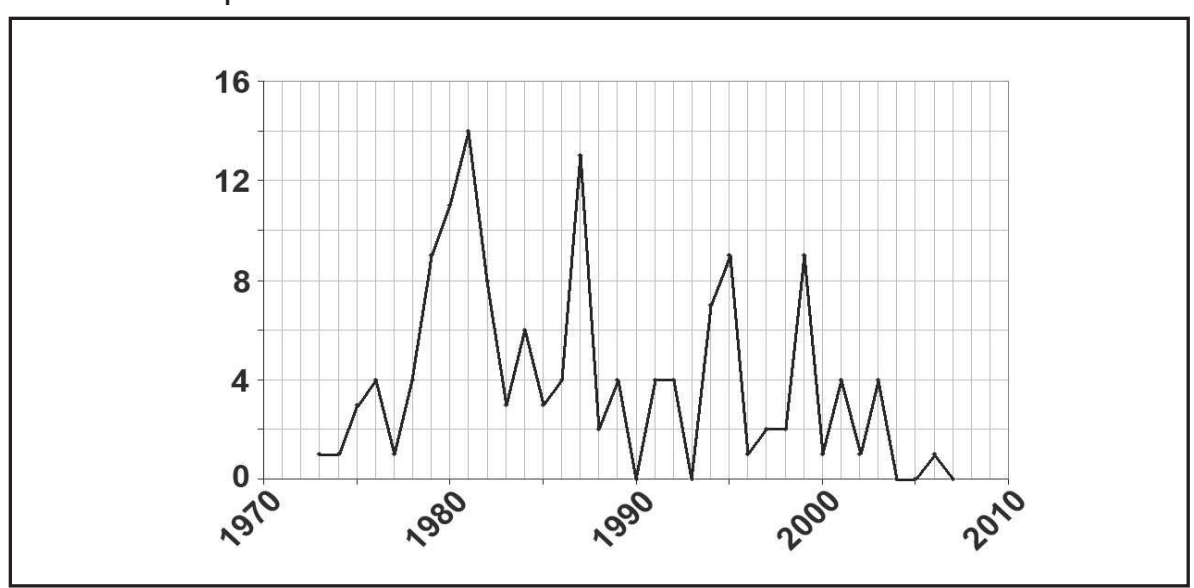

\section{Patentes por País/Organização}

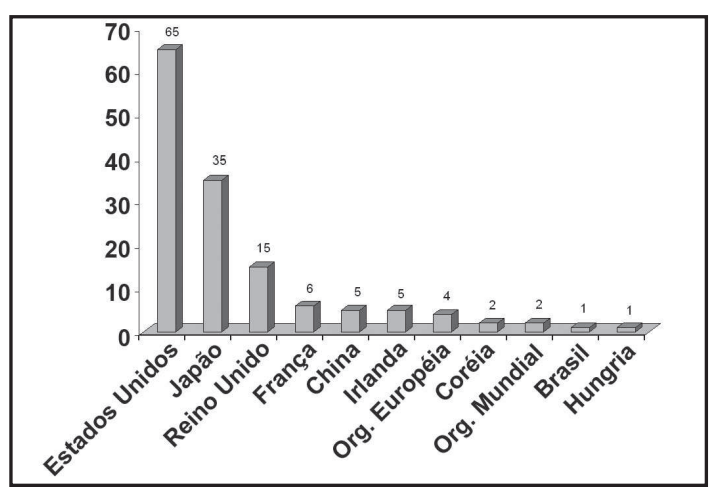

3. Patentes por Principais Inventores

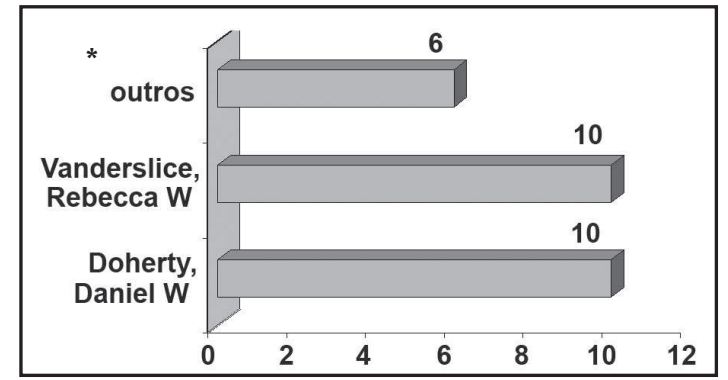

* Weisrock William P, Homma Taira; Nagura Shigehiro, Murofushi Kanji

\section{Patentes por Empresa}

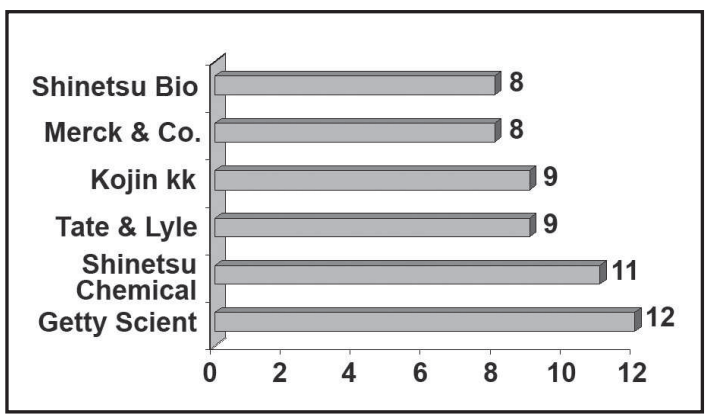

5. Distribuiç̧ão por código

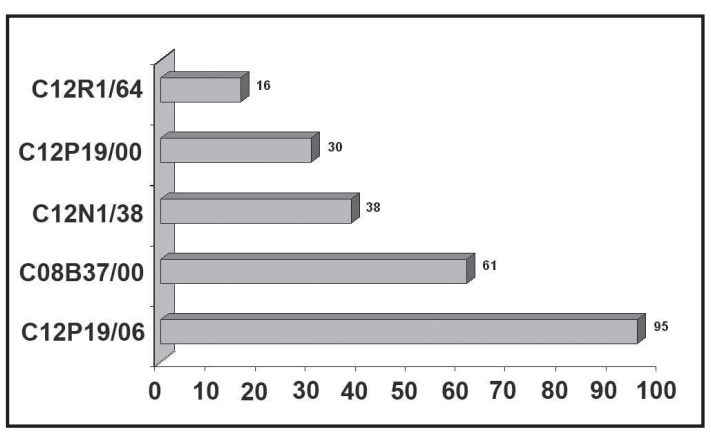

C12R1/64 = Xanthomonas

C12P19/00 $=$ Preparação de compostos contendo radical sacarídeo

C12N1/38 = Estimulação de crescimento por remoção de um composto químico

C08B37/00 = Preparação de polisacarídeos não descritos em C08B1/00 ou C08B 35/00 C12P19/06 = Xanthana

\section{Conclusões}

O início dos registros se deu em 1973.

Os Estados Unidos têm o maior número de depositantes, os dois inventores que mais têm registros nessa área (14\% dos registros) e cerca de $46 \%$ do número de registros de patentes. 0 Japão tem $24 \%$ das patentes.

A maioria das patentes analisadas focavam o estudo da xanthana e mais de $12 \%$ era relacionada com preparação de componentes contendo radicais sacarídeos

Flávia Silva Cunha é aluna de graduação em Engenharia Química da UFBA e bolsista ITI do Núcleo de Inovação Tecnológica da Universidade Federal da Bahia. Participou anteriormente de cursos do INPI e de treinamentos da Rede NIT-NE. 